PREPRINT

\title{
Perceptions Concerning Intergenerational Education from the Perspective of Participants
}

\author{
Juan Lirio Castro \\ Social Sciences Faculty, University of Castilla-La Mancha, \\ Talavera de la Reina, Toledo, Spain \\ David Alonso González \\ Social Work Faculty, Complutense University, Madrid, Spain \\ Immaculada Herranz Aguayo and Enrique Arias Fernández \\ Social Sciences Faculty, University of Castilla-La Mancha, \\ Talavera de la Reina, Toledo, Spain
}

\begin{abstract}
This article presents an evaluation of an intergenerational education experience at the University of Castilla-La Mancha (Spain). For this evaluation, following a review of the literature regarding the state of the issue, we undertake an analysis of benefits and disadvantages from the perspective of the participants. Among the benefits we find that the majority of those questioned would repeat the program, and that classroom atmosphere improved notably. Participants listed the exceptional nature of the program and the teachers needing to make methodological adjustments to improve the experience (the pace of teaching, adaptation to the profile of the participants) among the disadvantages.
\end{abstract}

This work presents an evaluation of an intergenerational education experience at the University of Castilla-La Mancha, the participants being young Social Education undergraduate students and students from the University Program for Older Adults. We agree with Sáez (2002) that, in older adult classes in Spanish universities, intergenerational projects and programs must have taken place about which we have little information, and that investigating these projects and programs is imperative for pedagogical research. In this context, we outline a program being carried out at the University of Castilla-La Mancha with the intention of analyzing both the positive aspects of the intergenerational approach being followed and improvements that could be made to it.

Sáez defines intergenerational education as "processes and procedures which are supported and legitimized by emphasising cooperation and interaction among any two or more generations,

Address correspondence to David Alonso González, Student Vice Dean, Social Work Faculty, Complutense University, 28223 Madrid, Spain. E-mail: dalonso@ucm.es 
securing the sharing of experiences, knowledge, abilities, attitudes, and values, in order to increase respective levels of self-esteem and personal self-realization. The aim is to change and be transformed in learning with others" (Sáez, 2002, p. 29). Meanwhile, in a UNESCO document, intergenerational programs are defined as "vehicles for the purposeful and ongoing exchange of resources and learning among older and younger generations for individual and social benefits" (Hatton-Yeo \& Ohsako, 2001, p. 5)

Sánchez and Díaz (2007, p. 11) present the principal components of an intergenerational program after analyzing the works of Newman (1998), Bressler, Henkin, and Adler (2005), Granville (2002), and Feldman, Mahoney, and Seedsman (2002). Sánchez and Díaz conclude that "A reliance on community (with its participation, involvement, development, and attention to real needs); the implementation of good Intergenerational Program (IP) planning and management; and the fostering of collaboration between organizations (networking) are the components that coincide most in the four analyses used" (p. 11).

Interest in intergenerational interaction and social contact stems from the potential of this contact in terms of the exchange of knowledge, abilities, information, ideas, and values (Lloyd, 2008). We also find that various approaches exist in relation to what intergenerational education is and what it deals with. Sáez (2002) presents the following three definitions:

1. A type of education fostering the promotion of knowledge about relationships between generations. This would make the "intergenerational" theme the center of attention of the curriculum chosen for what we call intergenerational education. The aim would be to clarify what generations are, how they are characterized, and how they are formed, and so on.

2. A type of education with the ultimate aim of intergenerationality. A type of education aiming to change or reconstruct intergenerational relationships. Here, intergenerationality is the purpose rather than the content.

3. An educational process in which people from diverse generations participate merely by dint of belonging to those generations. In this definition, the context of participation is what gives rise to the use of the "intergenerational" adjective.

Concerning the benefits of this type of program, Muñoz (2002) affirms that intergenerational participation offers beneficial effects as much to the older generation (in physical, psychological, and affective terms) as to the rest of the population. Muñoz further adds that, via intergenerational participation, people of different ages will do the following:

- Be able to share talents, resources, experiences and so on, thereby exchanging services with beneficial results, both individually and collectively.

- Overcome myths and respective stereotypes,

- Introduce new roles and perspectives for older and younger people,

- Improve self-esteem and understanding, establishing new bonds among generations,

- Strengthen the role of family ties as the nucleus of society.

However, for this to be possible, warm and positive intergenerational relationships entailing attention, cooperation and solidarity are necessary. Support of every kind (affective, instrumental, etc.) must be assured, and the relationships must allow for the fostering of self-esteem, autonomy, freedom, and the development of group and community spirit. 
We therefore distinguish between intergenerational relationships and intergenerational contact. Intergenerational relationships are those leading to exchange between people of different ages (in our case, exchange of opinions, sharing learning-teaching tasks, jointly developing knowledge). Intergenerational contact, by contrast, involves people of different ages sharing space and time without necessarily being involved in exchange, and where this exchange does occur, it is by chance and not continued.

Garcia (2003) also sets out certain premises of intergenerational education: (a) intercultural dialogue; (b) freedom; (c) shared motivation; (d) relationship based on equality; (e) achieving life goals. Research concerning educational programs for older adults and intergenerational programs has explicitly pointed to the effects of intergenerational interaction (Meshel \& McGlynn, 2004).

In general, intergenerational programs appear to enjoy a favorable reception and produce positive effects, as indicated by writers such as: Orduna and Burgui (2001) in relation to a program involving younger students and older adults in Navarra, Spain; Martínez de Miguel (2003), presenting the University Specialist Course program in gerontology: Socioeducational Intervention with Older Adults, in which both younger students and older adults participate in postgraduate study; and, finally, Holgado and Jiménez (2008), presenting the Pontifical University of Salamanca program in which certain subjects from the university program for older adults are offered (to a total of 20 older adults and 20 younger students from various undergraduate degree courses within the university), and are recognized as elective subjects for younger students.

\section{INTERGENERATIONAL EDUCATION IN UNIVERSITY PROGRAMS FOR OLDER ADULTS}

The university programs for older adults in Spain are an educational proposal of a cultural nature, which older adults may take without prior qualifications. As the programs are offered in different universities, they have different characteristics and may be classified as follows:

1. Specific programs: aimed exclusively at older adults, with an adapted study plan and even different classes from those used in the ordinary university.

2. Integrated programs: consisting of opening ordinary classes to older students, with such students being treated in the same way as everyone else.

3. Catalan model: managed by older adults and their associations, programs offered consist of conference cycles regarding topics of interest.

4. Mixed model: tends to be partly specific and partly integrated.

While there is a tendency to refer to the social integration of older adults and the creation of social networks as being among the aims of university programs for older adults in Spain, allusions to the intergenerational issue are few. In this sense, ensuring that older adults increase their social contacts and reach may be considered as the key theme of these kinds of study, with an absence of development and reflection concerning intergenerationality in such programs. Specifically, if we analyze this aspect in university programs for older adults, we find that - of more than 50 programs in existence-only one is entirely integrated and, hence, intergenerational. That program is the Nau Gran of the University of Valencia, with the remaining programs being of a 
specific kind or following the Catalan model (conference-focused). We may also mention that, in certain other programs, there is the possibility of older students studying some material together with younger students, thereby initiating programs of this kind or preparing older students for the second cycles of study offered by the university. (The first and second cycles refer to university programs for older adults; they do not follow the Bologna model of bachelor's and master's degrees.)

Within the context of university education of older adults, intergenerationality undoubtedly plays its most significant role in what are known as integrated second cycles.

The aim of these is to continue courses begun in specific programs, are they are different in the sense that the older adults themselves freely choose the areas they wish to study according to their interests, shaping individualized learning itineraries that are fully integrated into ordinary university classes over two academic years. This means that older adults, in the two years of the second cycle, will be coexisting with the younger university students. If we analyze the number of universities that have implemented second cycle studies in Spain, we find that - of more than 50 universities - only 12 offer this type of study program (around 25\%), of which, half (6) are integrated. The integrated second cycle programs in Spain are found in the following universities: Cádiz, Córdoba, Seville (designated Normalized Program), Valladolid (designated Open Modality), Jaime I of Castellón, and Castilla-La Mancha.

\section{Intergenerational Education in the José Saramago University for Older Adults}

The Integrated Second Cycle Program at the José Saramago University for Older Adults, part of the University of Castilla-La Mancha, began its activity in the academic year 2004/2005. Offering 36 learning credits, students pass the course by following two learning itineraries (in our case, one itinerary specialized in Social Sciences and the other in Health Sciences), composed of various subjects from the areas of Social Education, Social Work, Cultural Anthropology, Occupational Therapy, and Speech Therapy. In this manner, older students freely select the subjects they wish to study over two academic years from the choices offered by the university. Perhaps due to the variety of options relating to these subjects, only $10 \%$ of older students taking the specific program continue their studies in the integrated program; older students feel that the latter may have a greater degree of difficulty given that it involves ordinary university teaching. Reviewing the objectives of this second cycle of studies, we find the aims of encouraging integration of older students into appropriate subjects and of facilitating intergenerational exchange in the classroom.

With relation to the way in which the university encourages transition towards an integrated second cycle in which older students enter conventional university classes, we find the following:

- At the commencement of the integrated program, an information session is held to assist older students in understanding the objective of the program, the subjects offered, and other issues related to the everyday university dynamic. In turn, the students are motivated, supported, and encouraged in their new learning process to remove prejudices and insecurities. 
- Considerations taken into account in determining the choice of subjects offered for the second cycle, in addition to the type of subject, include whether the lecturer teaching the subject is aware of the older adults university program and the profile of the students therein. Priority is given to those instructors who actually provide teaching in the specific program (with regard to the Jose Saramago University program for older adults, the details for subject selection come from the university itself).

- Monitoring of the process of incorporation into ordinary classes. In this sense, both the coordinators and the lecturers participating in the specific integrated program try to guide and advise the older students concerning any doubts or difficulties which may arise (location of new classes, new timetables, etc.). The coordinators of the university for older adults also provide any information that may be pertinent, via the tutoring schedule.

We are nevertheless aware that all these forms of assistance, while positive in terms of the educational process of the students, do not directly ensure that each lecturer, in each subject offered and each class, adopts the intergenerational approach that can and should be followed. We, therefore, present the program involving the subject of Gerontological Pedagogy, given its status as one of the subjects aiming to adopt an intergenerational approach. The program was designed and developed bearing in mind the plan that students from two groups-from Social Education undergraduates and from the university program for older adults—would be involved.

\section{AN INTERGENERATIONAL EDUCATION PROGRAM IN GERONTOLOGICAL PEDAGOGY}

The obligatory subject Gerontological Pedagogy, taught by professor Juan Lirio Castro, forms part of the schedule for the third year of the undergraduate degree in Social Education; it is also offered as an elective subject in the integrated program for older adults. Two types of students attend: Social Education undergraduates and older students from the integrated program. Social Education is a four-year degree worth 240 ECTS credits, and it trains students to carry out socio-educational work with various groups (those groups include older adults). The subject focuses on the aging process and considering the reality of this group (myths regarding old age, resources and programs, principal difficulties in terms of quality of life, etc.), with the aim of learning to design and carry out educational action with this population sector.

This particular characteristic of Gerontological Pedagogy — tackling aging and older adults in an educational context as the objects of study-means that the presence of older adults in the class has a special relevance, given that the subject analyzes many age-related aspects that older students either have experienced or are experiencing on a personal level.

The presence of older adults in the class, therefore, offers a golden opportunity to interweave theory with the real experiences of people currently going through this time of change. In a certain sense, these older adults can act as critical observers of gerontological theory and the approaches adopted in social education.

Furthermore, the aim of Gerontological Pedagogy is to be an experiment in intergenerational education for which the following methodological approach is adopted: 


\section{Welcoming Older Students into the Integrated Cycle}

Prior to the arrival of older students into the class, during a class in the previous semester, the lecturer explains the imminent incorporation of the older students to the younger students. The concept of a university for older adults is explained as are the learning methods, objectives, and so on. Finally, preparations are made so that the new students, on arrival, will be made to feel comfortable and welcome in the subject to be studied together.

To date, younger students have tended to utilize various methods to get to know the older ones, including organizing meetings with coffee and cake to greet their older colleagues. It is worth mentioning that, in some years, the older students have responded to this welcome by writing thank-you notes, giving the younger students home-made desserts, and so on.

In addition to the events organized by the younger students, the lecturer will also entrust a task to small mixed groups of younger and older students. The assignment consists of choosing a place where the group can enter into a small dialogue, with the objective of getting to know one another. Younger students are also to investigate why the older students are attending the university for older adults. Older students are to learn why the younger students have chosen Social Education as a future profession. In this fashion, members of the group become aware of one another and recognize each other as colleagues (learning names, where other students come from, their motivations, and so on).

\section{Incorporation of Older Students into the Normal Class Dynamic}

Once the older students have been incorporated into the class, the process by which they each become one more student of the subject begins. To achieve this, the lecturer works explicitly towards inclusion and participation of students in the ordinary subject dynamic, so older and younger students become involved in the program in the following way:

1. At the beginning, an initiation activity is undertaken, consisting of imagining how our lives will be in 30 years. This involves the younger students imagining being 30 years older than they are while the older students imagine being 30 years younger. The aim of this is to develop awareness of the passage of time, facing aging and understanding it as a dynamic process. Where there are people from different generations in the same class, the lecturer can adapt the task according to the profiles of the students and provide two sets of instructions: while younger students perform the exercise by adding 30 years to their lives, older people remove 30 years from theirs. In this manner, in addition to reflecting on the issues previously identified, it is also possible to compare the lifestyles of both generations at different historical stages.

2. The lecturer uses, as part of the didactic methodology, questions to appeal to the students to articulate their prior knowledge and experiences related to the content of the subject. Direct questions are asked of all students, including the older adults. For example, students are asked about the positive and negative aspects of retirement.

3. At certain moments, debates take place regarding aspects of gerontological theory in which all students, whether younger or older, are expected to involve themselves and offer their own perspectives. 
4. In general, both younger and older students participate in the different learning tasks set in class. In this manner, younger and older students play equal roles in the tasks assigned (shared reading of a text, practical case analysis, considering the tasks of the social educator in the various areas of education for older adults, viewing and analyzing documentaries, analyzing press releases, etc).

5. On some occasions, the lecturer instructs a group of older students to carry out a specific task that must later be brought to the group. For example, the group may be directed to complete a work on retirement, associated experiences, and ways the group has found of dealing with it. This type of task is enriching for everyone, given that the group as a whole assists in the process of comparing theoretical knowledge with real experience. Older students feel useful and capable of completing work, and, in turn, the classroom atmosphere changes for the better.

\section{CHARACTERISTICS OF THE EDUCATIVE EXPERIENCE IN AN INTERGENERATIONAL CONTEXT}

\section{Method}

With the intention of investigating the program undertaken in the Gerontological Pedagogy subject in which younger and older students had shared classes, we decided to evaluate the project. For this purpose, we developed a self-complete questionnaire for the subjects to answer, that was organized around two types of questions. The first type referred to sociodemographic aspects and to the characterization of the group ( 3 questions); the second type of questions related to perspectives on the intergenerational experiment (13 questions).

After analysis of the questionnaires using the SPSS version 19.0 (a total of 47 questionnaires were completed, with open questions-later recoded-and closed questions), we present a descriptive analysis using frequency tables which set out the influence of intergenerational education on the educational process of the participants. The questionnaires were distributed in an ordinary class in May 2009.

\section{Results}

\section{General Data}

The analyzed group is composed of younger students (18-30 years) (66\%) and students from the University of Older Adults (34\%, whose ages range from 50 to 71 years). The increasing proportion of females in classes is a notable general phenomenon, and it is also observable in this program, with $85 \%$ of questionnaire respondents being female.

In terms of the academic qualifications of the older students, it should be stressed that more than $60 \%$ of older participants in the program have elementary studies. The remainder have middle or higher educational qualifications.

When asking the respondents if they had intergenerational contact outside the classroom (Table 1), more than $80 \%$ indicated that they did. But this high figure relates not so much to the fact of having such contact outside the classroom as to the places where intergenerational contact 
TABLE 1

In Which Context Did These Contacts Occur? (Multiple Answer) (\%)

\begin{tabular}{lc}
\hline In the family environment & 44.2 \\
In the work environment & 16.8 \\
In the context of leisure activities & 14.3 \\
In the context of social organizations & 13 \\
Others & 11.7 \\
Total & 100 \\
\hline
\end{tabular}

is established. Within these intergenerational contacts, we consider that those occurring in a family or work environment, together amounting to $60 \%$ of the total, are representative of more obligatory spaces. This is where contact is incidental rather than the express purpose of the situation, as opposed to $27 \%$ of the contacts occurring in social organizations and leisure activities, these being spaces of wider participation and enjoyment of free time, for which reason intergenerational contact continues to be limited to traditionally established spaces.

Regarding the expectations of the respondents concerning their presence in the class (Table 2), it is worth emphasizing that over $50 \%$ of respondents considered that everyone would be equal, giving an impression of parity in relation to the other group, whether that other group comprised younger or older persons.

\section{Evaluating the Experience}

Concerning the participants' evaluation of the program, almost $47 \%$ described the activity as a personal experience, or enriching on a personal level (Table 3). It is also worth highlighting that $25 \%$ responded with "don't know" or did not respond at all, giving no hint as to whether their assessment of the program was positive or negative.

Ninety-five percent $(95 \%)$ of respondents demonstrated interest in repeating the program. Only $2 \%$ considered that they would not repeat this type of program because they felt it did not work. Among the motives cited by respondents when asked why they would repeat the program (Table 4), three aspects stand out from the rest: around 38\% considered that it would help them develop a different view and understanding of others, $33 \%$ would repeat the experience due to its enriching nature, and nearly $18 \%$ would repeat because it would encourage intergenerational contact.

TABLE 2

What Were You Expecting at the Start of the Experience with Respect to the Location in Classroom of Your Generation's Group? (\%)

\begin{tabular}{lr}
\hline Everyone equal & 51.1 \\
My group as leaders & 19.1 \\
Only attendance & 8.5 \\
Students invited to class & 6.4 \\
Others & 4.3 \\
Don't know/no answer & 10.6 \\
Total & 100
\end{tabular}


TABLE 3

Following this Interegenerational Relationship Experience as Part of Your Learning Process, Could You Summarize what the Experience Meant for You (Experiences of Relationships with Somenone from Another Generation in Classroom Activities, Feelings, Anecdotes, Doubts, Conflicts)? (\%)

Personal experience

Personally enriching

Changed conceptions

Assisted in understanding of subject/provided an example

When asked which group had participated more in the program (Table 5), 51\% of respondents replied that both older and younger students had participated equally.

The motives presented for the conclusion that both groups had participated in equal measure were that this allowed the groups to exchange views and increase mutual understanding and because a positive climate had been generated (Table 6). Among those who considered that the older students had participated more, the view that this group was more predisposed towards participating stands out. On the other hand, those who felt the younger students had participated more believed this to be the case because that group had more obligations and work to undertake.

If we focus on what took place within the class (Table 7), positive comments stand out at more than $75 \%$ of respondents, although $55 \%$ considered that the relationship was very satisfactory but

TABLE 4

Would You Repeat this Type of Experience? What Are the Reasons for Repeating the Experience? (\%)

\begin{tabular}{lc}
\hline Different view/understanding of others & 37.8 \\
Enriching experience & 33.3 \\
Intergenerational contact & 17.8 \\
If the offer was extended & 4.4 \\
Don't know/no answer & 6.7 \\
Total & 100 \\
\hline
\end{tabular}

TABLE 5

Which Age Group Participated More? (\%)

$\begin{array}{lr}\text { Both equally } & 51.1 \\ \text { Younger group a little more } & 21.3 \\ \text { Older group a little more } & 12.8 \\ \text { Younger group much more } & 2.1 \\ \text { Younger group much more } & 8.5 \\ \text { Don't know/no answer } & 4.3 \\ \text { Total } & 100\end{array}$


TABLE 6

What Reasons Did They Have for Participating More? (\%)

Older students participated more

Younger students participated more

Both participated equally
Greater predisposition towards participation $71.4 \%$

Obligation $53.8 \%$

Exchange and jointly improved understanding 50\%

one-time. This was corroborated when the respondents were asked which factors should be stressed to encourage intergenerational relationships. It is notable that over $40 \%$ of respondents supported the idea of carrying out more activities of this kind, such as increasing or extending the program (see Table 8).

It is worth emphasising that $70 \%$ of respondents consider that the university system encourages intergenerational relationships. On this point, it would be useful to analyze if, to date, the system has genuinely encouraged intergenerational relationships or simply intergenerational contact. In this sense we might evaluate whether the presence in classes of people of distinct age groups does, in fact, lead to new types of relationship. Over $80 \%$ of respondents considered the program to have improved the group atmosphere in class, which also points to the advantages of intergenerational education.

Our question concerning whether the lecturer needed to change the class dynamic in the context of intergenerational education produced curious answers (Table 9). Seventy-two percent considered that no change was necessary, a result which contradicted the answers to our question about how to improve the program. In that latter context, $66.7 \%$ of respondents stated they would adapt rhythm $(33.3 \%)$, adjust objectives to profile (16.7\%), and be more dynamic (16.7\%). These

TABLE 7

Do You Think There Was an Intergenerational Relationship in the Classroom? (\%)

\begin{tabular}{lc}
\hline Very satisfactory but punctual relationship & 55.3 \\
Effective intergenerational relationship & 21.3 \\
Class shared but no relationship & 19.1 \\
Unsatisfactory and punctual relationship & 4.3 \\
Total & 100 \\
\hline
\end{tabular}

TABLE 8

What Would You Include to Encourage Intergenerational Relationships? (\%)

$\begin{array}{lr}\text { More intergenerational group activities } & 36.2 \\ \text { Change distribution within class } & 10.6 \\ \text { Will/motivation } & 8.5 \\ \text { Greater communication } & 6.4 \\ \text { Greater number of older adults } & 6.4 \\ \text { Increase or extend program } & 4.3 \\ \text { Don't know/no answer } & 27.7 \\ \text { Total } & 100\end{array}$


TABLE 9

How Does the Classroom Dynamic Need to Change when Working with People from Different Generations? (\%)

\begin{tabular}{|c|c|}
\hline Adapt rhythm & 33.3 \\
\hline Adjust objectives to profiles & 16.7 \\
\hline More dynamic & 16.7 \\
\hline Favorable treatment for older students & 16.7 \\
\hline Don't know/no answer & 16.7 \\
\hline Total & 100 \\
\hline \multicolumn{2}{|c|}{$\begin{array}{l}\text { TABLE } 10 \\
\text { In General, and as a Conclusion, Could You Tell Us the Level } \\
\text { of Satisfaction with the Experience from } 1 \text { to } 7 \text {, where } 1 \text { Means } \\
\text { Not At All Satisfactory and } 7 \text { Very Satisfactory? }(\%)\end{array}$} \\
\hline 1 & 2.1 \\
\hline 3 & 2.1 \\
\hline 4 & 8.5 \\
\hline 5 & 19.1 \\
\hline 6 & 36.2 \\
\hline 7 & 31.9 \\
\hline Total & 100 \\
\hline
\end{tabular}

results effectively indicate that the lecturer would have to modify his/her teaching methodology to adapt to the intergenerational nature of the class.

In general, participants evaluated the program very positively, with an average rating of 5.79 out of 7 (Table 10).

The number of positive responses (Table 11, multiple answers) received (90) far outweighs the number of negative responses (Table 12, multiple answers) regarding the program (31). It is also worth emphasizing that, of the respondents, 8 did not offer any answer to the question regarding positive aspects of the program, while 28 did not mention any negative aspects.

Finally, when respondents were asked what they considered to be the fundamental characteristics of people from the other generation (Table 13), more than 50\% indicated that they saw those people as active, open, and motivated. More than $20 \%$ focused on the satisfactory relationship they enjoyed with members of the other group.

\section{TABLE 11}

Please Indicate Three Positive Aspects Regarding the Experience of Sharing a Classroom with People from Another Generation (Multiple Answer) (\%)

\begin{tabular}{lr}
\hline Learning or contributing experiences & 28.6 \\
Knowledge/accepting others & 26.5 \\
Integenerational contact & 15.3 \\
Good atmosphere & 11.2 \\
Mutual enrichment/satisfaction & 10.2 \\
Don't know/no answer & 8.2 \\
\hline
\end{tabular}


TABLE 12

Please Indicate Three Negative Aspects Regarding the

Experience of Sharing a Classroom with People from Another Generation (Multiple Answer) (\%)

\begin{tabular}{lr}
\hline Classroom distortion & 13.6 \\
Fear of rejection & 6.8 \\
Differing requirements & 5.1 \\
Lack of flexibility & 5.1 \\
Lack of attendance in class & 3.4 \\
Others & 8.5 \\
Don't know/no answer & 47.5 \\
Total & 100 \\
\hline
\end{tabular}

\section{DISCUSSION}

Some research indicates the value of including intergenerational programs in the curriculum, with the aim of improving knowledge of the learning process and dispelling negative myths regarding aging (Angiullo, Whitbourne, \& Powers, 1996; Larkin \& Newman, 1997). The results of research, both quantitative and qualitative, indicate that programs help to create a more realistic image of aging and foster more positive attitudes towards older adults (Knapp \& Stubblefield, 2000).

In this regard, it can be highlighted that in the case of Spain, the objective of intergenerational exchange appears as part of numerous university programs for older adults. However, it appears that few programs are genuinely focused on this aspect. It appears that intergenerational education plays a greater part in the second cycles of programs, particularly in Integrated Programs. In spite of this, few programs or systematic evaluations exist regarding what is actually happening in classes. We, therefore suspect that, very probably, instead of real intergenerational education, what actually occurs in the majority of cases is intergenerational contact. In this regard, we are in agreement with various authors who indicate that positive results emanate more from personal learning and community service than from formal learning (Cavanaugh, 2001). Even so, intergenerational education programs receive very positive evaluations (Orduna \& Burgui, 2001; Muñóz, 2002; Martínez de Miguel, 2003). In general, it stands out that all participating generations benefit from this type of program (O'Quin, Bulot, \& Johnson, 2005).

TABLE 13

How Did the People from Another Generation with Whom You Have Shared Classes over the Last Few Months Seem to You? (\%)

\begin{tabular}{lc}
\hline Open/active and motivated people & 51.1 \\
Satisfactory relationship & 21.3 \\
Same as the other group/age had no influence & 10.6 \\
Don't know/no answer & 17 \\
Total & 100
\end{tabular}


From the program carried out in the course of Gerontological Pedagogy, we can present the following conclusions:

- The intergenerational education program appears to have been positively evaluated. This conclusion is reinforced by the results presented in Table $3(27.7 \%$ as a personal experience, $19.1 \%$ personally enriching, $12.8 \%$ changed conceptions, $8.5 \%$ assisted in understanding of subject/provided an example, and $4.3 \%$ improved relationships). And, of course, there is the $95 \%$ who would repeat the program.

- Concerning what took place within the class, positive comments stand out at over $75 \%$, although $55 \%$ considered that the relationship was very satisfactory but punctual. Eighty percent $(80 \%)$ of respondents indicated that an improved group atmosphere represented a principal advantage of intergenerational education.

- Although $72 \%$ stated that the lecturer would not need to change his/her class methodology to provide intergenerational education, the question of how the program could be improved elicited suggestions of adapting the rhythm (33\%), adjusting objectives for the two generations (17\%), and increasing intergenerational classroom contact (17\%), implying that some changes ought to be made.

- The general level of satisfaction regarding program, on a scale of 1-7, was 5.79, highlighting the positive evaluation of the program on the part of the respondents.

- Concerning the positive and negative aspects of the program, we find that the number of positive responses received (90) (multiple answers) far outweighs the number of negative comments on the program (31) (multiple answers).

- With respect to the practical implications, having analyzed the program, we conclude that the participants think that in similar programs the lecturer should employ a dynamic teaching method $\mathrm{He} / \mathrm{she}$ should offer different activities that would facilitate exchange among people of different generations such as adapting the rhythm of the class and bearing in mind the differing motivations that various participants may have.

Martínez de Miguel (2003) indicates that one of the problems faced by society is the distancing and lack of communication among different generations. On many occasions, younger and older generations hold reciprocally negative views regarding each other. In this regard, intergenerational programs, combining learning and exchange and involving planned interaction between younger people and older adults, can lead to mutual benefits (Newman \& Smith, 1997).

For our part, we consider that intergenerational education programs lead to increased valuing of others and personal enrichment. This happens via an exchange of experiences when undertaking joint tasks that leads to improved communication among generations and the creation of channels among realities, which, often, are not so different. Without question, intergenerational education in this sense would contribute to a bridging of the gap between generations and the creation of social networks-aspects which, in and of themselves, justify programs such as the one reviewed in this article.

Finally, although we considered the evaluation of the experience of intergenerational education to be positive, it is our view that in the future such evaluation should be extended across a larger number of subjects. This would be in addition to undertaking a more detailed analysis of variables involved in the evaluation of experiences (age, sex, previous education, and so on). 


\section{REFERENCES}

Angiullo, L., Whitbourne, S. K., \& Powers, C. (1996). The effects of instruction and experience on college students' attitudes toward the elderly. Educational Gerontology, 22, 483-495.

Bressler, J; Henkin, N., \& Adler, M. (2005). Connecting generations, strengthening communities. A toolkit for intergenerational program planners. Philadelphia, PA: Center for Intergenerational Learning.

Cavanaugh, J. (2001). Learning and doing: The importance of service-learning in gerontology. Educational Gerontology, 27, 117-124.

Feldman, S., Mahoney, H., \& Seedsman, T. (2002). Building intergenerational capacity. A national study of intergenerational programmes. Melbourne, Australia: Alma Unit for Research on Ageing, Victoria University.

García, J. (2003). Espacios de la educación intergeneracional [Intergenerational education realms]. In M. Bedmar \& I. Montero (Coords), La educación intergeneracional: Un nuevo ámbito educativo [Intergenerational Education: A new educative field] (pp. 13-16). Madrid, Spain: Dykinson.

Granville, G. (2002). A review of intergenerational practice in the UK. Stoke-on-Trent, UK: Beth Johnson Foundation.

Hatton-Yeo, A., \& Ohsako, T. (Eds.). (2001). Programas intergeneracionales: Política pública e implicaciones de la investigación. Una perspectiva internacional [Intergenerational programs: Public policy and research implications: An international perspective]. Hamburg, Germany: Instituto de la UNESCO para la educación.

Holgado, M. A., \& Jiménez, A. (2008). Una propuesta metodológica para potenciar las relaciones intergeneracionales [A methodological proposal to increase intergenerational relations]. In M. C. Palmero (Coord.), Formación universitaria de personas mayores y promoción de la autonomía personal. Políticas socioeducativas, metodologías e innovaciones [University education for elderly people and personal autonomy promotion. Socioeducative policies, methodologies and innovations] (pp. 245-253). Burgos, Spain: Universidad de Burgos.

Knapp, J. L., \& Stubblefield, P. (2000). Changing students' perceptions of aging: the impact of an intergenerational service learning. Educational Gerontology, 26(7), 611-621.

Larkin, E., \& Newman, S. (1997). Intergenerational studies: A multi-disciplinary field. In K. Brabazon \& R. Disch (Eds.), Intergenerational approaches in aging: Implications for education, policy and practice (pp. 5-16). New York, NY: Haworth.

Lloyd, J. (2008). The state of intergenerational relations today. A research and discussion paper. London, UK: International Longevity Centre.

Martínez De Miguel, S. (2003). La educación de personas mayores como derecho social: Diferencias con otras generaciones y posibilidades de encuentro [Elderly people education as social right: Differences among other generations and encountered possibilities]. In M. Bedmar \& I. Montero (Coords), La educación intergeneracional: Un nuevo ámbito educativo [Intergenerational education: A new educative field] (pp. 157-167). Madrid, Spain: Dykinson.

Meshel, D. S., \& McGlynn, R. P. (2004). Intergenerational contact, attitudes, and stereotypes of adolescents and older people. Educational Gerontology, 30, 457-479.

Muñóz, I. M. (2002). La participación educativa como fundamento de la integración intergeneracional [Educative participation as principle of intergenerational integration]. In J. Díaz \& M. Bedmar (Coords), Hacia la educación intergeneracional [Towards educational gerontology] (pp. 79-92). Madrid, Spain: Dykinson.

Newman, S. (1998). Intergenerational programs: Program management components. Generations Together X Annual Intergenerational Training Institute. Pittsburgh, PA: Generations Together.

Newman, S., \& Smith, T. B. (1997). Developmental theories as the basis for intergenerational programs. In S. Newman, C. R. Ward, T. B. Smith, J. O. Wilson, \& J. M. McCrea (Eds.), Intergenerational programs: Past, present, and future (pp. 3-19). Bristol, PA: Taylor \& Francis.

O'Quin, J., Bulot, J. J., \& Johnson, C. J. (2005). Sustaining intergenerational service-learning in gerontology education. Educational Gerontology, 31(1), 41-49.

Orduna, M. G., \& Burgui, R. (2001). Una experiencia combinada de educación gerontológica y gerontología educativa: Los talleres formativos para personas mayores [A combined experience of gerontological education: Formative workshops for elderly people]. In G. Orduna \& Y. C. Naval (Eds.), Gerontología educativa [Educative gerontology] (pp. 297-307). Barcelona, Spain: Ariel.

Sáez, J. (2002). Hacia la educación intergeneracional. Concepto y posibilidades [Towards intergenerational education. Concepts and possibilities]. En J. Sáez (Coord.), Pedagogía social y programas intergeneracionales: educación de personas mayores [Social pedagogy and intergenerational programs: Elderly people education] (pp. 99-112). Málaga, Spain: Aljibe.

Sánchez, M., \& Díaz, P. (2007). Components of an intergenerational programme. In M. Sánchez (Dir.), Intergenerational programmes evaluation (pp. 6-12). Madrid, Spain: IMSERSO. 